\title{
Pattern of cutaneous infections in pediatric age group - A clinico-observational study
}

\section{Mrinal Gupta}

\author{
Treatwell Skin Centre, Jammu, India
}

Corresponding author: Dr. Mrinal Gupta, E-mail: drmrinalgupta@yahoo.com

\begin{abstract}
Background: Among the various pediatric health problems, skin conditions constitute a significant proportion. Cutaneous problems can cause significant morbidity in the pediatric population. The pattern of skin problems in pediatric population differs from adults with infections and infestations being the most common problems followed by conditions like eczema and psoriasis. Aims and Objectives: We carried out this study to assess the clinical pattern of infections and infestation in pediatric age group. Materials and Methods: It was a prospective, observational study carried out over a period of two years in which two hundred children aged between 0-18 years, presenting with cutaneous infections in our centre were included. A detailed history, complete dermatological examination, along with routine investigations wherever required were recorded in a predesigned proforma. Results: The study group comprised of 200 children (M: F 114:86), with 44 children aged <5 years, 80 between $5-10$ years and $76>10$ years of age. Infections were seen in 164 children while infestations like scabies and lice were seen in 36 children. Bacterial infections were the most common infection seen in 64 children, followed by fungal infections in 56 and viral infections in 44 children. Scabies was the most common infestation seen in 28 children while lice infestation was seen in 8 children. Conclusions: The dermatoses such as infections and infestations are very common in the pediatric age group.
\end{abstract}

Key words: Pediatric dermatoses; Infections; Infestations; Impetigo

\section{INTRODUCTION}

Pediatric dermatology is a highly specialized subentity of dermatology practice. Skin diseases are a major health problem in the pediatric age group with children constituting around $30 \%$ of all outpatient visits to the dermatologist [1]. Cutaneous problems can cause significant morbidity in the pediatric population. The pattern of skin problems in pediatric population differs from adults with infections and infestations being the most common problems followed by conditions like eczema and psoriasis.

We carried out this study to assess the clinical pattern of infections and infestation in pediatric age group.

\section{MATERIALS AND METHODS}

It was a prospective, observational study carried out over a period of two years in which two hundred children aged between 0-18 years, presenting with cutaneous infections in our centre were included. A complete history including age, sex, duration of the disease, family history complete dermatological examination, along with appropriate investigations such as KOH examination, Tzanck test, Gram's staining, hematological investigation, biochemical investigations and skin biopsy etc., wherever required were recorded in predesigned proforma.

\section{RESULTS}

The study group comprised of 200 children (M:F 114:86), with 44 children aged $<5$ years, 80 between $5-10$ years and 76 children $>10$ years of age. Majority of children $(n=124)$ belonged to urban background while 76 were from a rural areas and most of the children were school-going $(n=172)$. Bacterial infections were the most common infection seen in $32 \%(n=64)$ 
children, followed by fungal infections in $28 \%(\mathrm{n}=56)$ and viral infections in $22 \%(\mathrm{n}=44)$ children. Scabies was the most common infestation seen in 28 children while lice infestation was seen in 8 children. Bacterial infections were the most common infection in patients aged $<5$ years whereas fungal infections were more common in children aged $>10$ years. The pattern of various infections and infestations in our study group is presented in Table 1. Family history of similar infections and infestations was present in $22 \%$ cases.

\section{DISCUSSION}

The pattern of skin lesions in children is different from adults and is greatly influenced by climatic factors, dietary patterns, and socioeconomic status. Infections and infestations are the most common dermatoses encountered in the pediatric population. Different studies have reported the prevalence rates of infections and infestations ranging between $32-85 \%$ in the pediatric population with cutaneous dermatoses [2-5]. They are a cause of significant morbidity in the pediatric population. Skin diseases are the most frequent diseases of school children in many developing countries. The school environment makes children vulnerable to the cross transmission of communicable skin diseases among themselves and their family [6] The prevalence of pediatric dermatoses is higher in rural areas as compared to urban areas in relation to poor socioeconomic status, poor personal hygiene, overcrowded, families lack of general awareness, lack of education, sanitation and specialized health facilities [7].

Table 1: Pattern of infections and infestations in the study population

\begin{tabular}{|c|c|c|c|c|}
\hline & Age $<5$ yrs & $5-10$ yrs & $>10$ yrs & Total \\
\hline \multicolumn{5}{|l|}{ Bacterial 64} \\
\hline Folliculitis & 6 & 16 & 10 & (32) \\
\hline Impetigo & 12 & 10 & 2 & (24) \\
\hline Secondary infections & 2 & 2 & 2 & (6) \\
\hline Acute paronychia & 0 & 0 & 2 & (2) \\
\hline \multicolumn{5}{|l|}{ Fungal 56} \\
\hline Dermatophytosis & 4 & 10 & 12 & (32) \\
\hline Candidiasis & 14 & 0 & 2 & (16) \\
\hline Pityriasis versicolor & 2 & 0 & 6 & (8) \\
\hline \multicolumn{5}{|l|}{ Viral 44} \\
\hline Molluscum & 6 & 8 & 2 & $(16)$ \\
\hline Warts & 4 & 4 & 6 & $(14)$ \\
\hline Varicella & 2 & 5 & 3 & $(10)$ \\
\hline Hand foot mouth disease & 3 & 1 & 0 & (4) \\
\hline Pityriasis rosea & 0 & 3 & 1 & (4) \\
\hline \multicolumn{5}{|l|}{ Infestations 36} \\
\hline Scabies & 9 & 5 & 14 & (28) \\
\hline Pediculosis & 0 & 3 & 5 & (8) \\
\hline
\end{tabular}

In our study, bacterial infections were the most common, seen in $32 \%$ children with folliculitis being the most common infection, seen in $16 \%$ followed by impetigo in $12 \%$. It was similar to the studies by various researchers, who also observed bacterial infections to be the most common pediatric skin infection $[4,5]$ (Fig. 1). Fungal infections of the skin were the second most common infection in our study, seen in $28 \%$ children. The incidence of fungal infections has been reported to vary from $3.3 \%$ to $8.5 \%$ in various other studies $[8,9]$.Dermatophytic infections like tinea corporis, tinea cruris and tinea faciei were more common in older children while candidal infections like intertrigo were more common in infants and younger children (Fig. 2). Pityriasis versicolor was also more common in the older age group owing to increased sweating tendency.

Viral infections were seen in $22 \%$ of our study group. Reddy et al reported an incidence of $40 \%$ of viral

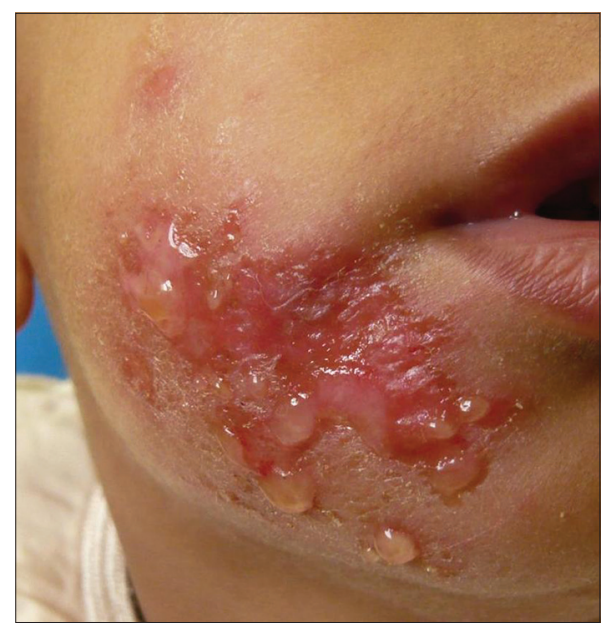

Figure 1: Bullous impetigo in a 3-year old child.

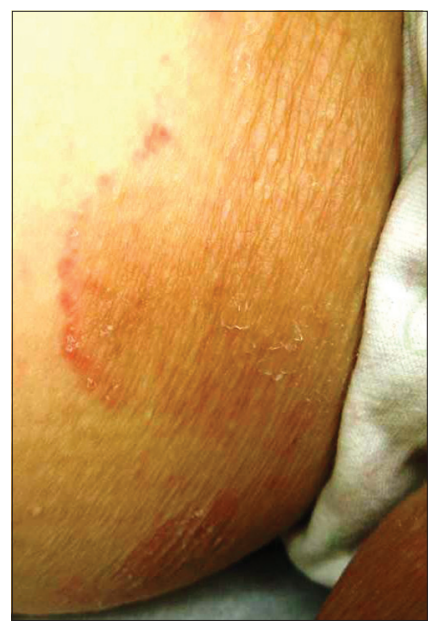

Figure 2: Tinea cruris in a 8-year old child. 


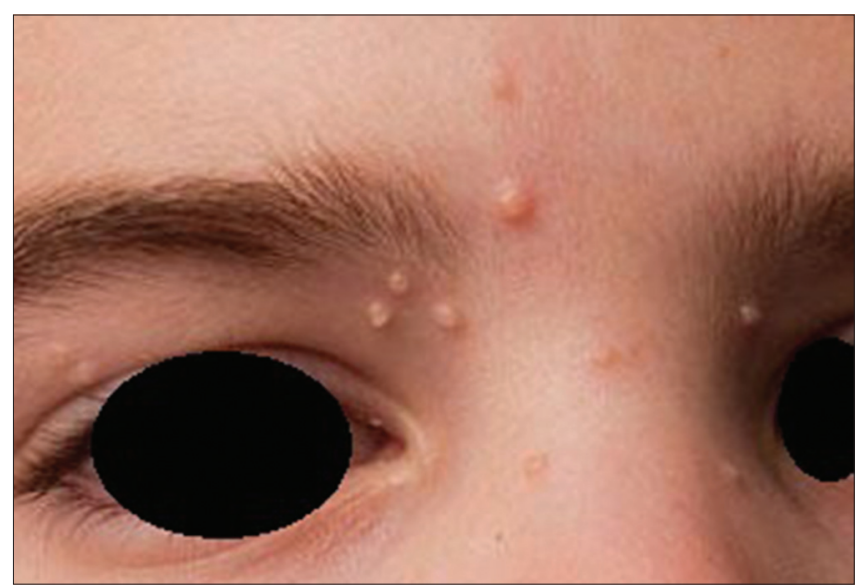

Figure 3: Molluscum contagiosum in a 5-year old child.

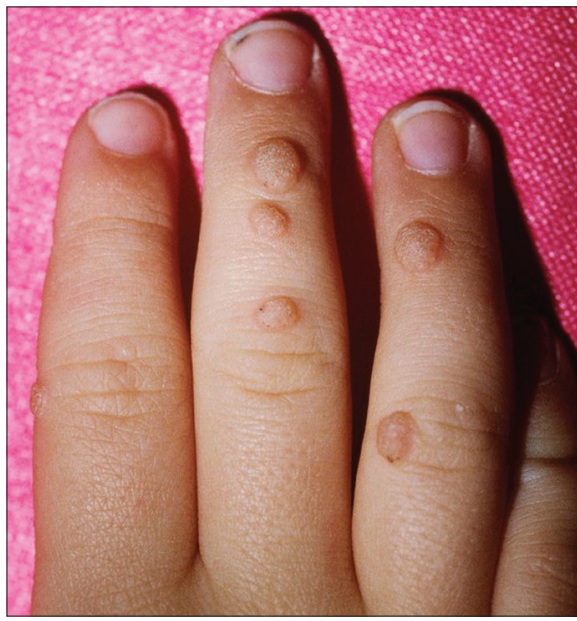

Figure 4: Multiple warts in a 7-year old child.

infections [9]. Molluscum contagiosum was the most common viral disease in our study seen in $8 \%$ cases, followed by warts in $7 \%$, varicella in $5 \%$, hand foot mouth disease and pityriasis rosea in $1 \%$ each. Reddy et al also observed molluscum to be the most common viral infection (38\%) followed by warts in 20\% [9] (Figs. 3 and 4). Scabies was the most common infestation in our study, seen in $14 \%$. The incidence of scabies has been reported to vary from $5 \%$ to $22 \%$ in different studies. A family history of scabies was seen in 22 out of 28 patients which can be attributed to its mode of transmission by close contact.

Our study had few limitations. It was conducted in a single center and sample size was small. A large, prospective multicentric study needs to be conducted to know more about pediatric infective dermatoses.

\section{CONCLUSIONS}

The dermatoses such as infections and infestations are very common in the pediatric age group with bacterial infections being the most common infections followed by fungal infections. A detailed knowledge about the pattern of pediatric dermatoses is useful in implementing essential changes in health education and disease control.

\section{Statement of Human and Animal Rights}

All procedures followed were in accordance with the ethical standards of the responsible committee on human experimentation (institutional and national) and with the Helsinki Declaration of 1975, as revised in 2008 .

\section{Statement of Informed Consent}

Informed consent was obtained from all patients for being included in the study.

\section{REFERENCES}

1. Jain N, Khandpur S. Pediatric dermatoses in India. Indian J Dermatol VenereolLeprol. 2010;76:451-4.

2. Balai M, Khare AK, Gupta LK, Mittal A, Kuldeep CM. Pattern of pediatric dermatoses in a tertiary care centre of South West Rajasthan. Indian J Dermatol. 2012;57:275-8.

3. Nagarajan K, Thokchom NS, Ibochouba K, Verma K, Bishurul Hafi NA. Pattern of pediatric dermatoses in Northeast India. Indian J Paediatr Dermatol 2017;18:286-91.

4. Poudyal Y, Ranjit A, Pathak S, Chaudhary N. Pattern of pediatric dermatoses in a Tertiary Care Hospital of Western Nepal. Dermatol Res Pract. 2016;2016:6306404.

5. Banerjee S, Gangopadhyay DN, Jana S, Mitra C. Seasonal variations in pediatric dermatoses. Indian J Dermatol. 2010;55:44-6.

6. Thakare S, Singh A, Madnani A, Lakhar B. Scenario of pediatric dermatoses in rural population of Central India. Glob J Dermatol Venereol. 2013;1:7-10.

7. Sacchidanand S, Sahana MS, Asha GS, Shilpa K. Pattern of pediatric dermatoses at a referral centre. Indian J Pediatr. 2014;81:37580.

8. Awal G, Singh SP, Sharma S, Kaur J. Spectrum and pattern of pediatric dermatoses in under five population in a tertiary care centre. Int J Res Dermatol. 2016;2:69-76.

9. Reddy VS, Anoop T, Ajayakumar S, Bindurani S, Rajiv S, Bifi J. Study of clinical spectrum of pediatric dermatoses in patients attending a Tertiary Care Center in North Kerala. Indian J Paediatr Dermatol. 2016;4:266-72.

Copyright by Mrinal Gupta. This is an open-access article distributed under the terms of the Creative Commons Attribution License, which permits unrestricted use, distribution, and reproduction in any medium, provided the original author and source are credited.

Source of Support: Nil, Conflict of Interest: None declared. 